\title{
The Challenges of Multimorbidity from the Patient Perspective
}

\author{
Polly Hitchcock Noël, PhD ${ }^{1,2}$, Michael L. Parchman, MD, MPH', , John W. Williams, Jr., MD, MHS ${ }^{3,4}$, \\ John E. Cornell, $P h D^{1,2,5}$, Lee Shuko, MS ${ }^{7}$, John E. Zeber, $P h D^{1,2}$, Lewis E. Kazis, ScD 6,7, \\ Austin F. S. Lee, $P h D^{6,8,9}$, and Jacqueline A. Pugh, $M D^{1,2}$
}

${ }^{1}$ VERDICT/South Texas Veterans Healthcare System, San Antonio, TX, USA; ${ }^{2}$ University of Texas Health Science Center, San Antonio, TX, USA; ${ }^{3}$ Durham VA Medical Center, Durham, NC, USA; ${ }^{4}$ Duke University, Durham, NC, USA; ${ }^{5}$ GRECC/South Texas Veterans Healthcare System, San Antonio, TX, USA; ${ }^{6}$ Center for Health Quality, Outcomes, and Economic Research Edith Nourse Rogers Memorial Veterans Hospital, Bedford, VA, USA; ${ }^{7}$ Boston University School of Public Health, Boston, MA, USA; ${ }^{8}$ College of Management, National Cheng Kung University, Tainan City, Taiwan; ${ }^{9}$ College of Science, Sungkyunkwan University, Seoul, South Korea.

BACKGROUND: Although multiple co-occurring chronic illnesses within the same individual are increasingly common, few studies have examined the challenges of multimorbidity from the patient perspective.

OBJECTIVE: The aim of this study is to examine the self-management learning needs and willingness to see non-physician providers of patients with multimorbidity compared to patients with single chronic illnesses.

DESIGN: This research is designed as a cross-sectional survey.

PARTICIPANTS: Based upon ICD-9 codes, patients from a single VHA healthcare system were stratified into multimorbidity clusters or groups with a single chronic illness from the corresponding cluster. Nonproportional sampling was used to randomly select 720 patients.

MEASUREMENTS: Demographic characteristics, functional status, number of contacts with healthcare providers, components of primary care, self-management learning needs, and willingness to see nonphysician providers.

RESULTS: Four hundred twenty-two patients returned surveys. A higher percentage of multimorbidity patients compared to single morbidity patients were "definitely" willing to learn all 22 self-management skills, of these only 2 were not significant. Compared to patients with single morbidity, a significantly higher percentage of patients with multimorbidity also reported that they were "definitely" willing to see 6 of 11 non-physician healthcare providers.

CONCLUSIONS: Self-management learning needs of multimorbidity patients are extensive, and their preferences are consistent with team-based primary care. Alternative methods of providing support and chronic illness care may be needed to meet the needs of these complex patients.

KEY WORDS: multimorbidity; multiple chronic illness; selfmanagement skills.

J Gen Intern Med 22(Suppl 3):419-24

DOI: $10.1007 / \mathrm{s} 11606-007-0308-\mathrm{z}$

(c) Society of General Internal Medicine 2007

\section{BACKGROUND}

Although multiple co-occurring chronic illnesses within the same individual are increasingly common, ${ }^{1-3}$ research on the effectiveness of interventions and outcomes for these complex patients is scarce. ${ }^{4}$ Even fewer studies have examined the challenges of multimorbidity from the patient perspective. Aside from the geriatric literature, exploration of patient-identified needs, barriers to self-care, coping skills, and treatment preferences have largely been disease-specific. A few recent qualitative studies have described barriers to self-management and coping strategies in relatively small samples of patients with multiple chronic illnesses. ${ }^{5-7}$ To more systematically assess a broader range of topics, we used mixed methods to identify the challenges of multimorbidity experienced by primary care patients served by the Veterans Health Administration (VHA).

The VHA is an ideal setting to explore chronic illness complexity because multimorbidity is highly prevalent among veterans. ${ }^{8}$ To initially identify the concerns and preferences of these complex patients, we conducted focus groups with 60 patients having 2 or more chronic illnesses at 8 geographically dispersed VHA primary care clinics. ${ }^{9}$ Not surprisingly, patients identified a number of negative impacts from multimorbidity, including polypharmacy, juggling multiple appointments, poor continuity of care, and difficulty accessing nonscheduled, urgent care. Problematic interactions with physicians were also mentioned, often in relation to specialty care, and included incidents in which providers had ignored concerns or provided conflicting advice. Most participants expressed overall satisfaction with their primary care physicians but were also appreciative of nonphysician providers. ${ }^{9}$ Lack of time and motivation interfered with self-management regimens, but knowledge and skills deficits were noted as contributing factors. Although this qualitative work provided important insights about the burdens of multimorbidity and its impact on health care, the extent to which these concerns differed from patients with a single chronic illness was not clear.

\section{OBJECTIVE}

The present study used a cross-sectional survey to compare the self-management learning needs of primary care patients with multiple chronic illnesses and patients with single chronic illnesses. Although we hypothesized that significantly more patients with multimorbidity would be willing to learn 
Table 1. Chronic Illnesses Used to Form Multimorbidity and Single Morbidity Groups

\begin{tabular}{lll}
\hline \hline & Multimorbidity & Single Morbidity \\
\hline Metabolic & $\begin{array}{l}\text { Hypertension, } \\
\text { Hyperlipidemia, Diabetes, }\end{array}$ & $\begin{array}{l}\text { Hypertension OR } \\
\text { Hyperlipidemia OR }\end{array}$ \\
& AND Ischemic Heart & Diabetes OR Ischemic \\
& Disease (patients required & Heart Disease ONLY \\
to have at least 3 of the 4 & \\
diseases) & \\
Obesity, Osteoarthritis, & Obesity OR osteoarthritis \\
Obesity & Low back pain, GERD, & OR low back pain OR \\
& AND Benign Prostatic & GERD OR Benign \\
& Hyperplasia (patients & Prostatic Hyperplasia \\
& required to have at least 3 & ONLY \\
& of the 5 diseases) & \\
Depression, PTSD, Other & Depression OR PTSD OR \\
Anxiety Disorder, Alcohol & Other Anxiety Disorder, \\
Psychiatric & Abuse, Substance Abuse, & OR Alcohol Abuse OR \\
& Bipolar Disorder, & Substance Abuse OR \\
& Schizophrenia (patients & Bipolar Disorder OR \\
& required to have at least 4 & Schizophrenia ONLY \\
& of the 7 diseases) & \\
\hline
\end{tabular}

various self-management skills than patients with single morbidity, we were uncertain whether this would only be true for certain types of skills. Assuming that nonphysician healthcare providers play an important role in providing skills training and other support services, we also compared multimorbidity and single morbidity patients' willingness to see different types of nonphysician providers. We hypothesized that multimorbidity patients would be more willing to see nonphysicians, but were unsure whether this would be true for only certain types of providers.

\section{PARTICIPANTS}

We developed a sample from primary care patients served by a Veterans Affairs Medical Center and its affiliated outpatient clinics in South Texas. Eligible patients had at least one primary care clinic encounter during the previous 13 months. For patients meeting visit eligibility criteria $(N=23,068)$, we extracted all primary and secondary encounter diagnoses, both inpatient and outpatient, for the previous 3 years from the VHA's electronic medical record system.

Using ICD-9 codes, the presence or absence of 45 diagnoses groups representing prevalent chronic illnesses in the veteran population was coded for each patient. ${ }^{10}$ The patients were then stratified into 3 multimorbidity clusters previously demonstrated to be the most highly prevalent among veterans ${ }^{10}$ and 3 patient groups with a single chronic illness from the corresponding cluster for a total of 6 separate groups (Table 1). The multimorbidity clusters were identified from a prior analysis using an agglomerative hierarchical clustering technique on the encounter diagnoses of 1.645 million primary care patients served by the VHA during a 4-year period (19972001). ${ }^{10}$ Although patients in the multimorbidity clusters could have other chronic diseases in addition to the diseases within their cluster, they could not have any of the diseases from the other 2 multimorbidity clusters. Patients in the single disease groups had only 1 of the 45 chronic illness diagnosis groups. We then used nonproportional sampling to randomly select 120 patients from each group for a total of 720 patients.

\section{MEASUREMENTS AND DATA COLLECTION}

Our mailed survey assessed demographic characteristics and functional status using the physical and mental component scores of the SF-12V. ${ }^{11}$ We also asked patients to report the number of times they had seen their primary care physician and any specialist physicians in the last 12 months, and whether the health care they had received was obtained from the VA only or from both VA and nonVA sources.

The 20-item Components of Primary Care Instrument (CPCI) was included to assess patients' perception of the delivery of 4 components or "attributes" of primary care services thought to be associated with quality of care: patient preference for their primary care physician, interpersonal communication with their primary care physician, the physician's accumulated knowledge of the patient, and coordination of care by the primary care physician. ${ }^{12}$ Each item consists of a stem with a Likert-type response on a 1-to- 5 scale anchored by "strongly disagree" and "strongly agree." Scale items are averaged with the score of 5 indicating the highest level of perceived delivery of the primary care component. CPCI ratings have been found to be associated with the delivery of preventive screenings and health habit counseling. ${ }^{13}$

We also constructed a 22-item scale to measure the extent to which patients were willing to learn self-management skills. The goal was to create a measure to assess patient-identified learning needs for individuals with multiple chronic illnesses as opposed to typical needs assessments that are diseasespecific (e.g., cancer) or setting-specific (e.g., inpatient). The scale reflected 12 "common tasks" for chronic illness previously identified through a literature review ${ }^{14}$ and 10 others identified through our earlier focus groups of veterans with multimorbidity. ${ }^{9}$ The scale uses a 5-point rating scale indicating patients' desire to learn each self-management skill $(4=$ would definitely want to learn, 3 = would probably want to learn, 2 = would consider learning, 1 = would probably not want to learn, and $0=$ would definitely not want to learn). Cronbach's alpha was 0.94, indicating good internal consistency. Principal component factor analysis with a promax rotation was used to examine construct validity and indicated that a 1-factor solution provided the best fit for the data.

We also included items assessing patients' willingness to receive care from 11 types of nonphysician healthcare professionals to help their primary care physician "to monitor their progress, teach self-management skills, or help them cope with their illness." Respondents rated their willingness to see each nonphysician on a 5 -point scale $(4=$ would definitely see to $0=$ would definitely not see). Because willingness to see a specific type of healthcare provider might be influenced by prior experience with that provider type, we also assessed whether or not participants had actually received care from each type of nonphysician in the past 6 months.

A survey containing the instruments described above was mailed to each eligible subject using a modification of Dillman's total design methodology. ${ }^{15}$ This approach uses a series of carefully spaced mailings to establish trust and reduce respondent burden, including a pre-notification letter, survey packet with return envelope, reminder postcard, and second survey packet to nonrespondents. Individuals not responding to the second mailed survey were contacted by phone to verify their address and offered a US $\$ 10.00$ incentive to return the survey. The study was approved by our institutional review board. 
Table 2. Comparisons of Single Morbidity and Multimorbidity Patients

\begin{tabular}{|c|c|c|c|}
\hline & $\begin{array}{l}\text { Single } \\
\text { morbidity, } \\
N=195\end{array}$ & $\begin{array}{l}\text { Multimorbidity, } \\
N=227\end{array}$ & $\begin{array}{l}p \\
\text { Value }\end{array}$ \\
\hline Males \% & 73 & 90 & $<0.001$ \\
\hline Median age & 50 & 57 & $<0.001$ \\
\hline European American \% & 55 & 59 & 0.42 \\
\hline $\begin{array}{l}\text { Received VA care } \\
\text { only (\%) }\end{array}$ & 41 & 57 & 0.002 \\
\hline $\begin{array}{l}\text { Saw } \mathrm{PCP}>4 \text { times } \\
\text { in past } 12 \text { months }(\%)\end{array}$ & 11.4 & 33.3 & $<0.001$ \\
\hline $\begin{array}{l}\text { Saw specialist physician } \\
>1 \text { time in past } 12 \\
\text { months }(\%)\end{array}$ & 32.4 & 53.9 & $<0.001$ \\
\hline Mean PCS $12 \mathrm{~V}(\mathrm{SD})^{*}$ & $39.5(7.1)$ & $34.8(7.4)$ & $<0.001$ \\
\hline Mean MCS-12V (SD)* & $42.8(10.3)$ & $38.6(12.1)$ & $<0.001$ \\
\hline \multicolumn{4}{|c|}{ Mean components of primary care subscale scores (SD) ${ }^{\dagger}$} \\
\hline Coordination of care & 3.0 & 3.3 & 0.02 \\
\hline Communication & 3.8 & 3.8 & 0.18 \\
\hline $\begin{array}{l}\text { Preference for usual } \\
\text { provider }\end{array}$ & 3.7 & 4.0 & $<0.001$ \\
\hline Accumulated knowledge & 3.0 & 3.3 & $<0.001$ \\
\hline $\begin{array}{l}\text { Mean self-management } \\
\text { learning skills score (SD) }\end{array}$ & $9.7(7.7)$ & $12.7(7.2)$ & $<0.001$ \\
\hline $\begin{array}{l}\text { Mean willingness to see } \\
\text { nonphysician providers } \\
\text { score }(\mathrm{SD})^{\S}\end{array}$ & $3.4(4.0)$ & $4.5(4.2)$ & 0.01 \\
\hline
\end{tabular}

*Higher scores indicate higher functioning

${ }^{\dagger}$ Higher scores indicate more positive experiences

${ }^{\ddagger}$ Scores indicate number of skills patients were "definitely willing" to learn

${ }^{\S}$ Scores indicate number of nonphysician provider types patients were "definitely willing" to see

\section{ANALYSIS}

We originally planned to compare the 6 groups on the various measures of interest. Tests of homogeneity of covariance matrices, however, found significant variance-covariance heterogeneity between groups, which is a violation of an underlying assumption of linear discriminant function analysis. When the 3 multimorbidity groups and the 3 single morbidity groups were combined, the variance-covariance matrices were found to be equivalent. We then compared the combined single morbidity group and the combined multimorbidity group on sociodemographic characteristics, functional status, primary care attribute scores, and other measures using $X^{2}$ on categorical variables and a nonparametric method (Wilcoxon test) on continuous measures that had nonnormal distributions. To facilitate ease of interpretation on the group comparisons, the 5-point ratings of "willingness to learn" the 22 selfmanagement skills and "willingness" to see the 11 nonphysician providers were dichotomized such that only ratings of "definitely willing" were conservatively coded as "yes" and all other responses were coded as "no." Missing responses on these scales were also coded as "no". The number of "definitely willing" responses for each scale was summed to yield a total self-management learning needs score (ranging from 0-22) and a total willingness to see nonphysician providers score (ranging from 0-11). Spearman correlation coefficients were used to examine the association between total self-management learning needs scores, total willingness to see nonphysician provider scores, and the CPCI subscale scores.

\section{RESULTS}

Of the 720 mailed surveys, 422 were returned. Twenty patients $(2.7 \%)$ were subsequently found to have moved with no forwarding address or to have died, yielding an overall adjusted return rate of $60 \%$. Multimorbidity patients were more likely to have returned surveys than those with a single chronic illness ( 64 versus $56 \% ; X^{2}=5.28 ; p=0.02$ ). As expected, patients in the multimorbidity groups were significantly older, more likely to be male, and had poorer functional status (Table 2). Significantly more multimorbidity subjects reported having received their health care from the VA only and seeing their primary care physician more than 4 times and their specialist physicians more than 1 time in the past year. They also rated their experiences on 3 of the 4 primary care attributes significantly more positive than the single morbidity patients.

On average, the total number of 22 self-management skills that multimorbidity patients "definitely" were willing to learn was significantly higher than the total number endorsed by single morbidity patients. Examination of the individual selfmanagement skills indicated that a higher percentage of multimorbidity patients compared to single morbidity patients were "definitely" willing to learn all 22 self-management skills; of these, only 2 were not significant ("meet responsibilities at home" and "reduce alcohol intake"; Table 3). There were interesting differences in the rank order of items endorsed by the 2 groups. For example, among multimorbidity patients, the

Table 3. Percent of Single Morbidity Versus Multimorbidity Patients "Definitely" Willing to Learn 22 Self-Management Skills

\begin{tabular}{|c|c|c|c|}
\hline $\begin{array}{l}\text { Self-management } \\
\text { skill }\end{array}$ & $\begin{array}{l}\text { Single } \\
\text { morbidity, } \\
N=195 \%\end{array}$ & $\begin{array}{l}\text { Multimorbidity, } \\
N=227 \%\end{array}$ & $\begin{array}{l}p \\
\text { Value }\end{array}$ \\
\hline $\begin{array}{l}\text { Monitor important } \\
\text { symptoms }\end{array}$ & 51.3 & 69.6 & $<0.001$ \\
\hline Use medications correctly & 56.9 & 74.9 & $<0.001$ \\
\hline $\begin{array}{l}\text { Manage medical } \\
\text { emergencies }\end{array}$ & 56.4 & 67.4 & 0.02 \\
\hline Eat healthy diet & 53.9 & 65.6 & 0.01 \\
\hline Lose weight & 44.6 & 62.1 & $<0.001$ \\
\hline $\begin{array}{l}\text { Exercise or stay physically } \\
\text { active }\end{array}$ & 52.8 & 63.0 & 0.03 \\
\hline Reduce stress & 59.0 & 68.3 & 0.047 \\
\hline $\begin{array}{l}\text { Talk to and question } \\
\text { physician }\end{array}$ & 48.2 & 66.5 & $<0.001$ \\
\hline $\begin{array}{l}\text { Identify or use resources in } \\
\text { community }\end{array}$ & 37.4 & 48.0 & 0.03 \\
\hline $\begin{array}{l}\text { Meet responsibilities at work } \\
\text { or home }\end{array}$ & 46.2 & 54.6 & 0.08 \\
\hline Adjust to physical limits & 46.2 & 63.0 & $<0.001$ \\
\hline $\begin{array}{l}\text { Get support from family or } \\
\text { friends }\end{array}$ & 40.5 & 51.5 & 0.02 \\
\hline Manage emotional reactions & 45.6 & 62.1 & $<0.001$ \\
\hline $\begin{array}{l}\text { Identify or use hospital } \\
\text { resources }\end{array}$ & 55.4 & 66.5 & 0.02 \\
\hline Handle finances or benefits & 44.1 & 55.1 & 0.02 \\
\hline Manage pain & 51.3 & 69.2 & $<0.001$ \\
\hline Improve sleep & 55.9 & 69.6 & 0.004 \\
\hline $\begin{array}{l}\text { Develop hobbies or leisure } \\
\text { activities }\end{array}$ & 34.4 & 52.0 & $<0.001$ \\
\hline Improve sexual relationship & 40.0 & 56.4 & $<0.001$ \\
\hline $\begin{array}{l}\text { Take care of spiritual or } \\
\text { religious needs }\end{array}$ & 33.9 & 48.5 & 0.002 \\
\hline Stop smoking & 8.7 & 23.4 & $<0.001$ \\
\hline Reduce alcohol intake & 8.7 & 12.8 & 0.18 \\
\hline
\end{tabular}


5 skills endorsed by the greatest percentage of patients were: use medications correctly, monitor important symptoms, improve sleep, manage pain, and reduce stress. The 5 skills endorsed by the greatest percentage of single morbidity patients were reduce stress, use medications correctly, manage medical emergencies, improve sleep, and identify or use hospital resources.

Compared to single morbidity patients, a significantly higher percentage of multimorbidity patients reported that they were "definitely" willing to see 6 of the 11 types of nonphysician healthcare providers to support their care: physician's assistant, psychologist, social worker, nutritionist, pharmacist, and "any health professional who works closely with and communicates with my doctor." A significantly higher percentage of multimorbidity patients compared to single morbidity patients also reported having received care from 6 of the 10 nonphysicians in the past 6 months: nurse, physician's assistant, psychologist, social worker, nutritionist, and pharmacist (Table 4).

Spearman correlation coefficients indicated that total selfmanagement learning needs scores were positively associated $(p<0.0001)$ with total scores of willingness to see the nonphysician providers. This suggests that as patients' willingness to learn self-management skills increased, so did their willingness to see nonphysicians. Furthermore, patients' willingness to learn self-management skills appeared to be strongly associated with their experiences of 3 of the 4 components of primary care: coordination of care $(p=0.0466)$, preference for usual provider $(p=0.0022)$, and accumulated knowledge of the provider $(p=0.0115)$, but not communication $(p=0.8760)$.

\section{CONCLUSIONS}

These results suggest that the self-management learning needs of veterans with multimorbidity are more extensive than those of patients with single chronic illnesses. Disease-specific skills such as blood glucose monitoring for diabetes or inhaler use for asthma are important aspects of chronic care, but the "generic" self-management skills assessed in our survey are relevant to most chronic illnesses. Although standardized group classes such as Lorig's Chronic Disease Self-Management Program can be an efficient method to teach generic selfmanagement skills, ${ }^{14}$ they may not adequately address all of the concerns of complex patients with multimorbidity. Of the 20 self-management skills endorsed by a significantly higher percentage of multimorbidity patients, several (e.g., improving sexual relationships) are not included among the topics covered in Lorig's program. ${ }^{14}$ This underscores the importance of the collaborative exploration of patient-identified problems and the development of individualized treatment plans.

Although the number of self-management skills endorsed by multimorbidty patients is quite large, it is not our intent to suggest that patients want to, or should even try to, learn 20 self-management skills at once. Indeed, recent research suggests that patients should focus on 1 behavior change at a time. ${ }^{16}$ It is our hope instead that primary care providers will be more cognizant of the broad range of needs and help patients prioritize skills training. Complex patients and their physicians, however, may disagree about which problems are most important to target. ${ }^{9}$ Selecting the wrong target or initiating too many changes at once may overwhelm patients and lead to poor adherence. ${ }^{16,17}$ Ideally, targets should be selected on the basis of importance, patient motivation, and readiness for change.

Significantly more multimorbidity patients also reported a greater willingness to see 6 of 11 different types of nonphysician professionals to support their care, teach self-management skills, and provide follow-up monitoring. Furthermore, the willingness to see all 11 types of nonphysicians was significantly associated with patients' self-management learning needs, although multimorbidity patients gave significantly better ratings on 3 of the 4 care components they received from their primary care physicians (PCP). The finding that multimorbidity patients gave higher ratings of their providers in terms of coordination of care, preference for usual provider, and accumulated knowledge is interesting, given that other studies suggest that chronic disease patients are usually less satisfied with their care. ${ }^{18}$ The CPCI appears to measure constructs that are independent from patient satisfaction. ${ }^{19}$ This may because, in part, of the fact that their frames of reference differ. Most satisfaction scales ask patients to rate a single visit or overall

Table 4. Percentage of Single Morbidity Versus Multimorbidity Patients Endorsing "Definitely" Willing to See 11 Different Types of Nonphysician Providers and Percentage Who Actually Saw Providers in Past 6 Months

\begin{tabular}{|c|c|c|c|c|c|c|}
\hline \multirow[b]{2}{*}{ Healthcare provider type } & \multicolumn{3}{|c|}{$\%$ Definitely willing to see provider } & \multicolumn{3}{|c|}{$\%$ Actually saw provider in past 6 months } \\
\hline & $\begin{array}{l}\text { Single } \\
\text { morbidity, } \\
N=195\end{array}$ & $\begin{array}{l}\text { Multimorbidity, } \\
N=227\end{array}$ & $\begin{array}{l}p \\
\text { Value }\end{array}$ & $\begin{array}{l}\text { Single } \\
\text { morbidity, } \\
N=195\end{array}$ & $\begin{array}{l}\text { Multimorbidity, } \\
N=227\end{array}$ & $\begin{array}{l}p \\
\text { Value }\end{array}$ \\
\hline Nurse & 41.5 & 49.8 & 0.09 & 29.2 & 42.3 & 0.005 \\
\hline Physician's assistant & 36.4 & 47.6 & 0.02 & 17.4 & 33.0 & $<0.001$ \\
\hline Psychologist & 28.2 & 45.8 & $<0.001$ & 11.3 & 27.8 & $<0.001$ \\
\hline Social worker & 22.6 & 33.9 & 0.01 & 5.6 & 15.9 & $<0.001$ \\
\hline Nutritionist & 32.3 & 45.8 & 0.005 & 5.6 & 24.7 & $<0.001$ \\
\hline Pharmacist & 28.7 & 43.2 & 0.002 & 13.9 & 27.8 & $<0.001$ \\
\hline Physical therapist & 37.4 & 44.1 & 0.17 & 9.2 & 14.1 & 0.12 \\
\hline Health educator & 32.3 & 39.2 & 0.14 & 4.1 & 8.8 & 0.0527 \\
\hline Chaplain & 21.5 & 23.4 & 0.68 & 3.6 & 5.3 & 0.40 \\
\hline Peer counselor & 22.1 & 28.2 & 0.15 & 9.7 & 11.9 & 0.48 \\
\hline $\begin{array}{l}\text { Any health professional who works closely with } \\
\text { and communicates with my doctor }\end{array}$ & 32.3 & 48.9 & $<0.001$ & NA & NA & NA \\
\hline
\end{tabular}


care, whereas the CPCI refers to experiences with a single physician. ${ }^{19}$ The results suggest that multimorbidity patients may understand that their PCPs often do not have the time to teach self-management skills or to check on patients' progress between scheduled appointments. It is also possible that quality interactions with their PCP increased patients' trust to see other providers.

It is important to note, however, that a significantly higher percentage of multimorbidity patients actually received care from 6 of the 11 types of nonphysicians in the last 6 months. Although it is possible that willingness to see nonphysician providers was associated with prior exposure, the percentages of patients who were definitely willing to see nonphysicians greatly exceeded the percentage of patients who had actually seen the same provider types by up to $30 \%$. While this suggests that patients desire to have more contact with nonphysicians than they currently do, at some point, multiple appointments might become burdensome. We did not assess how many different providers patients would find acceptable to receive care from at once, but presumably care from nonphysicians should also be prioritized to patient needs.

The finding that multimorbidity patients are willing to receive care from nonphysicians such as pharmacists is consistent with our earlier focus groups, which indicated that multimorbidity patients were very willing to work with nonphysicians as long as the care supplemented, but not eliminated, physician care. ${ }^{9}$ This is underscored by the fact that almost $50 \%$ of multimorbidity patients (versus $32 \%$ of single morbidity patients) were definitely willing to receive care from "any healthcare provider who works closely with and communicates with" their PCP. It is increasingly recognized that physicians need not, and should not, be the sole healthcare provider in primary care. ${ }^{20}$ Although multimorbidity patients appear willing to accept "team-based" care, they definitely want their PCP to be the team "leader."

The present study is limited by the self-report nature of the data, which may not reflect actual behavior. Moreover, our sample was derived from 1 healthcare system, making it difficult to generalize these results to other populations because VHA patients tend to be older, male, and to have more comorbid conditions. ${ }^{21,22}$ Unlike many studies that rely upon samples of convenience, however, the participants in the present study were randomly selected based upon encounter diagnoses representing specific "clusters" of multiple chronic illnesses. Although it is possible that the likelihood of being classified with multimorbidity based upon ICD-9 coding is confounded with increased healthcare contacts, our focus was on recognized chronic illness, not just symptom complaints. Furthermore, the significant differences in SF-12V scores increase our confidence that the multimorbidity group had significantly greater morbidity. We have no reason to believe that our findings of multimorbidity patients' willingness to learn self-management skills will not be true of other patients with multimorbidity, but we hope that others will replicate our work in different populations in different healthcare systems.

Despite the extent of multimorbidity in its patient population, the VHA has demonstrated continued improvements in quality and patient-reported satisfaction. ${ }^{23,24}$ Although these gains are largely attributed to the VHA's implementation of performance measurement and comprehensive electronic medical record, the VHA also transformed its care in the 1990s by shifting emphasis from the inpatient to the outpa- tient setting and assigning every patient a PCP. As the largest integrated healthcare system in the USA, the VHA also employs a large contingent of interdisciplinary, allied healthcare providers. The self-reported needs and preferences of patients with multimorbidity suggest that the integration of team-based care within primary care may help address the challenges of these complex patients.

Currently, however, two thirds of PCP work in autonomous solo or small group practices with limited support staff or capacity to provide skills training and proactive follow-up. ${ }^{25}$ Failure of third-party payers to reimburse these crucial components of chronic illness care is a contributing factor to the relative lack of this support in most primary care settings. ${ }^{17}$ Increasingly, resources for patient self-management support are available from government and not-for-profit foundation Web sites such as National Institutes of Health and the American Diabetes Association. Ultimately, new models of delivering comprehensive chronic illness care such as group clinics, automated telephone disease management programs, or home visits by physician extenders may help to expand these services to patients who need them.

Acknowledgment: The research reported in this paper was funded by the US Department of Veterans Affairs, Veterans Health Administration, Health Services Research and Development Service (grant \#01-110 and HBU \#02-197) and supported by the Agency for Healthcare Research and Quality (grant \#KO8 HSO13008-02). We also want to acknowledge the work of Kelly Montgomery, MPH, in extracting the encounter data to identify the study sample. The views expressed in this article are those of the authors and do not necessarily represent the views of the Department of Veterans Affairs. Some of the findings have been previously presented at the 2006 National HSR\&D Meeting and the 2004 and 2006 Academy Health Annual Meetings.

Conflict of Interest: None of the authors have any known conflicts that either could directly or indirectly, purposefully or inadvertently affect the conduct, outcome, or reporting of this research.

Corresponding Author: Polly Hitchcock Noël, PhD; VERDICT/ South Texas Veterans Healthcare System, 7400 Merton Minter Blvd, San Antonio, TX, USA (e-mail: noelp@uthscsa.edu).

\section{REFERENCES}

1. Wolff JL, Starfield B, Anderson G. Prevalence, expenditures, and complications of multiple chronic conditions in the elderly. Arch Intern Med. 2002;162:2269-76.

2. Tinetti ME, Bogardus ST, Agostini MD. Potential pitfalls of diseasespecific guidelines for patients with multiple conditions. N Engl J Med. 2004;371:2870-4.

3. Boyd CM, Darer J, Boult C, Fried LP, Boult L, Wu AW. Clinical practice guidelines and quality of care for older patients with multiple comorbid diseases: implications for pay for performance. JAMA. 2006;294:716-24.

4. Fortin $\mathbf{M}$, Lapointe $\mathbf{L}$, Hudon $\mathbf{C}$, Vanasse A. Multimorbidity is common to family practice: is it commonly researched? Can Fam Physician. 2005;51:244-5.

5. Bayliss EA, Steiner JF, Fernald DH, Crane LA, Main DS. Descriptions of barriers to self-care by persons with comorbid chronic diseases. Ann Fam Med. 2003;1:15-21.

6. Jerant AF, von Friederichs-Fitzwater MM, Moore M. Patients' perceived barriers to active self-management of chronic conditions. Patient Educ Couns. 2005;57:300-7.

7. Loeb SJ. African American older adults coping with chronic health conditions. J Transcult Nurs. 2006;17:139-47.

8. Kazis LE, Ren XS, Lee A, et al. Health status in VA patients: results from the Veterans Health Study. Am J Med Qual. 1999;14:28-38. 
9. Noël PH, Frueh BC, Larme AC, Pugh JA. Collaborative care needs and preferences of primary care patients with multimorbidity. Health Expect. 2005;8:54-63.

10. Cornell J, Pugh JA, Williams JW Jr, Kazis L, Lee A, Parchman M, Zeber J, Montgomery KA, Noël PH. Multimorbidity clusters: clustering binary data from a large administrative medical database. Applied Multivariate Research. 2007:12 (in press).

11. Kazis LE, Skinner K, Rogers W. Health status of veterans: physical and mental component summary scores (SF-12V). 1997 National Survey of Ambulatory Care Patients Executive Report. Washington, DC: Veterans Health Administration, Office of Quality and Performance; 1998.

12. Flocke SA. Measuring the attributes of primary care: development of a new instrument. J Fam Pract. 1997;45:64-74.

13. Flocke SA, Stange KC, Zyzanski SJ. The association of attributes of primary care with the delivery of clinical preventive services. Med Care. 1998;36:21-30.

14. Lorig KR, Sobel DS, Stewart AL, Brown BW Jr, Bandura A, Ritter P, Gonzalez VM, Laurent DD, Holman HR. Evidence suggesting that a chronic disease self-management program can improve health status while reducing hospitalization: a randomized trial. Med Care. 1999;37:514.

15. Dillman DA. Mail and telephone surveys: the total design method. New York: Wiley; 1978.
16. Glasgow RE, Davis CL, Funnell MM, Beck A. Implementing practical interventions to support chronic illness self-management. Jt Comm J Qual Saf. 2003;29:563-74.

17. Bodenheimer $\mathbf{T}$, Lorig $\mathbf{K}$, Holman $\mathbf{H}$, Grumbach $\mathbf{K}$. Patient selfmanagement of chronic disease in primary care. JAMA. 2006 288:2469-75.

18. Anderson GF. Physician, public, and policymaker perspectives on chronic conditions. Arch Intern Med. 2003;163:437-42.

19. Parchman ML, Noël PH, Lee S. Primary care attributes, healthcare system hassles, and chronic illness. Med Care. 2005;43:1123-9.

20. Safran DG. Defining the future of primary care: what can we learn from patients? Ann Intern Med. 2003;138:248-55

21. Wolinsky FD, Coe RM, Mosely RR. Veterans and nonveterans use of health services: a comparative analysis. Med Care. 1985;23:1358-71.

22. Kazis LE, Ren XS, Lee A, et al. Health status in VA patients: results from the Veterans Health Study. Am J Med Quality. 1999;14:28-38.

23. Perlin JB, Kolodner RM, Roswell RH. The Veterans Health Administration: quality, value, accountability, and information as transforming strategies for patient-centered care. Am J Manag Care. 2004;10:828-36.

24. Oliver A. The Veterans Health Administration: an American success story? Milbank Q. 2007;85(1):5-35

25. American Medical Association. Physician socioeconomic status 2005 2006 edition. Chicago, IL: American Medical Association; 2004 